\title{
PELATIHAN BUDIDAYA SAYURAN SECARA HIDRO-VERTIKULTUR DI DESA DATAH KARANGASEM SEBAGAI KEGIATAN MITIGASI BENCANA
}

\author{
M. Pharmawati ${ }^{1}$, Y. Ciawi ${ }^{2}$, L.P. Wrasiati ${ }^{3}$, I.M.A.S. Wijaya ${ }^{4}$
}

\begin{abstract}
ABSTRAK
Desa Datah, Kecamatan Abang, Karangasem termasuk ke dalam KRB (Kawasan Rawan Bencana) II akibat letusan Gunung Agung. Masyarakat tidak dapat merawat perkebunan dengan maksimal. Teknik hidrovertikultur dapat menjadi solusi karena merupakan teknik bertanam tanpa tanah dan nutrisi dialirkan dalam bentuk larutan. Berbeda dengan pertanian konvensional, dimana unsur hara dalam tanah tidak diketahui, sehingga hidroponik cocok sebagai teknik bertanam di lahan tandus seperti Desa Datah. Pertanian hidrovertikultur dapat dilakukan di tempat sempit, karena penanaman dilakukan pada wadah vertikal. Kegiatan ini bertujuan memberikan keterampilan bertanam sayuran secara hidro-vertikultur kepada petani dan pemuda STT yang ada di Banjar Tindih, Desa Datah, Kecamatan Abang, Karangasem. Kegiatan pertama dilakukan mulai bulan Juni 2018 meliputi persiapan alat dan bahan serta penjajagan lokasi. Kegiatan utama dilakukan tanggal 29 Juli 2018 yang diikuti oleh 26 orang yang dibagi dalam bentuk ceramah dan praktek. Ceramah mencakup pengertian hidroponik, alat dan bahan, cara pembibitan dan cara pembuatan nutrisi. Praktek yang dilakukan adalah membuat persemaian, membuat larutan nutrisi dan transfer bibit ke sistem hidroponik. Sebanyak 1 sistem hidro-vertikultur dipasang dan 3 sistem statis box juga dikerjakan. Kegiatan kedua dilakukan tanggal 30 September 2018.yang merupakan kegiatan evaluasi yang diikuti oleh 8 peserta. Pengamatan menunjukkan bahwa tanaman kangkung dapat tumbuh dengan baik, sedangkan tanaman selada pertumbuhannya tidak maksimal.
\end{abstract}

Kata kunci :hidroponik, Karangasem, sayuran, vertikultur

\begin{abstract}
Datah Village, Abang District, Karangasem belongs to the KRB (Disaster Prone Area) II due to the eruption of Mount Agung. Agricultural activity was affected by the eruption. Farmers in that area cannot fully control their plantation. Hydro-verticulture techniques can be a solution because it is a landless cultivation technique and nutrients are flowed in solution, while in conventional agriculture, the nutrients in the soil are unknown. Hydroponics is suitable as a technique for cultivating in barren lands such as Datah Village. Hydro-verticulture farming can be done in a narrow place, because planting is done in a vertical container. This activity aimed to provide hydro-verticulture vegetable farming skills to farmer and youth in Banjar Tindih, Datah Village, Abang District, Karangasem. The activities were carried out starting in June 2018 covering preparation of tools and materials. The main activity was held on 29 July 2018 which was attended by 26 people. Lecture was given on introduction to hydroponics, tools and materials needed and nutrients preparation. Practicum activities consisted of seed sowing, nutrient preparation and transferring seedlings to a hydroponic system. A total of 1 hydro-verticulture system was installed and 3 static box systems were also carried out. The second activity was held on 30 September 2018 which was an evaluation activity attended by 8 participants. Observations show that water spinach grew better than lettuce.
\end{abstract}

\footnotetext{
${ }^{1}$ Staf Pengajar Program Studi Biologi, Fakultas MIPA, Universitas Udayana, made_pharmawati@unud.ac.id.

${ }^{2}$ Staf pengajar Program Studi Teknik Sipil, Fakultas Teknik, Universitas Udayana, yenniciawi@yahoo.com

${ }^{3}$ Staf pengajar Fakultas Teknologi Pertanian,Universitas Udayana, wrasiati@ gmail.com

${ }^{4}$ Staf pengajar Fakultas Teknologi Pertanian,Universitas Udayana, anomsw@unud.ac.id
} 
Keywords: Hydroponic, Karangasem, vegetable, verticulture

\section{PENDAHULUAN}

Bertanam dengan teknik hidroponik akhir-akhir ini banyak dilakukan oleh masyarakat. Hidroponik merupakan teknik budidaya tanaman tanpa tanah dengan nutrisi terkontrol (Mas'ud, 2009). Terdapat beberapa variasi dalam hidroponik, antara lain merendam sistem akar dalam air yang disebut kultur air, atau menggunakan substrat dimana sistem akar berada dalam medium pertumbuhan yang disebut kultur agregat (Echeverria, 2008). Pada sistem hidroponik, nutrisi diberikan dalam bentuk cairan dengan komposisi unsur hara yang tepat. Dalam pertanian konvensional di lahan tanah, tanaman tidak mendapatkan nutrisi yang tersedia dalam jumlah yang tepat karena kandungan nutrisi pada tanah tidak diketahui. Di samping itu, tanah juga merupakan habitat bermacam-macam spesies dari organisme pengganggu tanaman (OPT) seperti gulma, larva, insekta maupun bakteri patogenik yang mengganggu dan merusak tanaman sehingga menurunkan hasil (Rosliani dan Sumarni, 2005).

Salah satu teknik variasi dalam budidaya sayuran secara hidroponik adalah teknik hidrovertikultur. Teknik vertikultur atau vertical culture merupakan sistem budidaya pertanian yang dilakukan secara vertikal atau bertingkat. Teknik verikultur dapat dikombinasikan dengan sistem hidroponik dan diberi nama hidro-vertikultur. Sistem budidaya pertanian secara vertikal merupakan konsep bertanam sayuran yang cocok untuk daerah lahan terbatas (Nofrinda, 2017).

Bertanam secara hidro-vertikultur tidak memerlukan lahan yang luas serta sangat efisien dalam penggunaan air (Roidah, 2014). Teknik bercocok tanam hidro-vertikultur ini merupakan aktivitas bertani yang dapat dilakukan oleh masyarakat yang terdampak bencana alam seperti bencana erupsi Gunung Agung, Bali. Bertanam secara hidro-vertikultur merupakan salah satu kegiatan mitigasi bencana sektor pertanian. Kegiatan mitigasi bencana dilakukan untuk mengurangi risiko dan dampak yang diakibatkan oleh bencana terhadap masyarakat yang berada pada kawasan rawan bencana. Teknik hidro-vertikultur memiliki beberapa keuntungan antara lain (1) Dapat dikerjakan di tempat yang sempit, (2) Sebagai alternatif untuk tanah yang tidak subur, (3) Mudah untuk dipindah, (4) Kualitas produk yang lebih baik (Susila, 2013; Nofrinda, 2017)

Letusan Gunung Agung, Karangasem, Bali telah berdampak besar pada perkonomian Bali. Diperkirakan kerugian mencapai Rp 1,5 sampai 2 triliun. Sebanyak 100 milyar dari total kerugian adalah di sektor pertanian (Detiknews, 2017). Produksi sayur dan buah yang menurun mengakibatkan suplay ke konsumen berkurang. Desa Datah, Kecamatan Abang, Karangasem termasuk kedalam Desa KRB (Kawasan Rawan Bencana) II (Jawa Pos, 2017). Beberapa banjar di Desa Datah yang berada di ketinggian merupakan banjar yang terdampak oleh erupsi Gunung Agung, Karangasem Bali.

Desa Datah bagian atas yang berada di lereng timur Gunung Agung seperti Banjar Kedampal merupakan banjar yang terdampak dimana masyarakat mengungsi ke banjar lainnya yang berada di bawah dan lebih aman seperti ke Banjar Tindih Desa Datah. Keadaan tersebut menyebabkan masyarakat tidak dapat merawat lahan pertanian sengan maksimal. Kondisi lingkungan yang cukup tandus di Desa Datah, menjadikan hidroponik sebagai pilihan ideal dalam bertanam sayuran.

Melalui kegiatan pengenalan budidaya sayuran secara hidro-vertikultur diharapkan masyarakat di Desa Datah. Karangasem dapat melakukan aktifitas pertanian di area sempit dan lingkungan kering, sehingga dapat memenuhi kebutuhan sayur di rumah tangga sendiri. Sistem hidrovertikultur merupakan sistem yang paling tepat untuk model usaha pertanian di daerah dengan 
tanah tandus karena media tanam dalam hidroponik bukan tanah dan nutrisi dalam bentuk cairan yang hanya perlu diganti 3 minggu sekali sehingga sangat efisien dalam penggunaan air, Di samping itu, produk saur hidroponik dapat menguntungkan dari segi kualitas dan kuantitas hasil, serta dapat memaksimalkan lahan yang sempit (Roidah, 2014).

Khalayak sasaran strategis pada kegiatan ini adalah petani, Desa Datah, (khususnya Banjar Tindih), Kecamatan Abang, Karangasem, Bali. Selain petani di Banjar Tindih, Desa Datah, para pemuda yang tergabung dalam STT (Sekaa Teruna Teruni) Desa Datah juga terlibat sebagai peserta pada kegiatan pelatihan ini.

\section{METODE PELAKSANAAN}

Metode yang digunakan mencakup persiapan alat dan bahan, kegiatan ceramah, praktek dan evaluasi. Ceramah terdiri dari pengenalan berbagai sistem hidroponik, pengenalan hidro-vertikultur berserta manfaat dan kelebihan sistem hidro-vertikultur, teknik persemaian dengan media rockwool, serta pengenalan macam-macam sayuran yang dapat ditanam dengan sistem hidrovertikultur. Pada pengenalan ini juga dijelaskan bahwa dalam hidroponik selain menggunakan air, dapat pula menggunakan media pertumbuhan non tanah yang ringan seperti sabut kelapa dan pakis (Nurlaeny, 2014). Selain sistem hidro-vertikultur, juga dijelaskan sistem pasif sederhana menggunakan kotak maupun botol bekas.

Praktek yang dilakukan meliputi pembuatan larutan nutrisi dimulai dari pembuaton stok nutrisi $A$ dan stok nutrisi $B$, serta pembuatan larutan nutrisi siap pakai $A B$ mix, pemilihan dan persemaian benih, penanaman atau pemindahan bibit ke sistem hidroponik dan pemeliharaan. Diskusi dengan peserta dilakukan selama ceramah dan praktek untuk meningkatkan pemahaman peserta.

Evaluasi terhadap kegiatan dilakukan berdasarkan antusiasme peserta dalam mengikuti pelatihan yaitu keaktifan peserta dalam diskusi dan praktek. Evaluasi juga dilakukan berdasarkan pengamatan terhadap hasil praktek penanaman sayuran.

\section{HASIL DAN PEMBAHASAN}

Kegiatan diawali dengan penyiapan alat dan bahan yang meliputi pembelian perangkat hidrovertikultur dan starter kit hidroponik statis serta benih beberapa sayur. Kegiatan pelatihan dilakukan tanggal 29 Juli 2018, dan evaluasi dilakukan tanggal 30 September 2018. Kegiatan tanggal 29 Juli 2018 diikuti oleh 26 peserta yang terdiri dari petani, pemuda anggota STT dan masyarakat umum di Banjar Tindih, Desa Datah, Karangasem, Bali (Gambar 3.1). Sayuran yang ditanam adalah sawi hijau, kangkung, selada hijau dan selada merah. Satu sistem hidro-vertikultur dipasang pada kegiatan ini (Gambar 3.2a) dan 3 sistem hidroponik pasif (statis) menggunakan starter kit hidroponik sederhana dalam bentuk kotak sterioform (Gambar 3.2b).

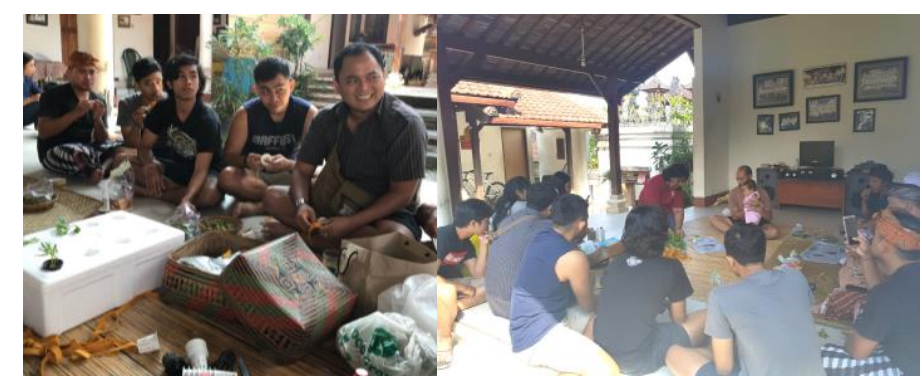

Gambar 3.1. Kegiatan Penanaman Bibit Sayuran pada Sistem Hidroponik 


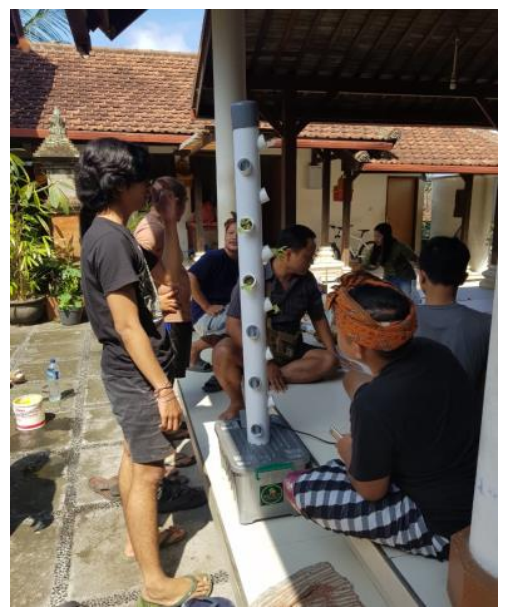

$\mathrm{b}$

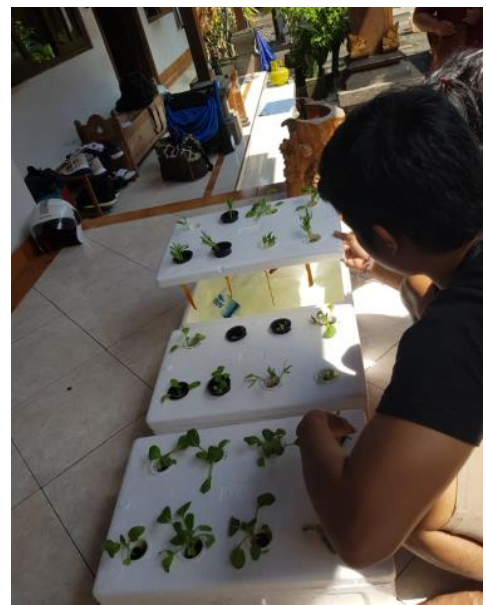

Gambar 3.2. Penanaman Bibit Sayur Pada Sistem Hidro-vertikultur (a); Penanaman Bibit Sayur Pada Sistem Sederhana Menggunakan Kotak Sterioform (b)

Bertanam secara hidroponik dapat dilakukan dengan cara yang sangat sederhana. Selain menggunakan kotak sterioform, kotak plastik bekas atau ember bekas juga dapat digunakan sebagai wadah (Gambar 3.3a). Cara lain yang lebih sederhana dengan memanfaatkan barang bekas adalah menggunakan botol bekas air mneral sebagai wadah. Pada kegiatan kali ini, penanaman sayur dengan memanfaatkan botol bekas air mineral juga dilakukan. Hal ini untuk memperkenalkan pentingnya 3R (reduce, reuse dan recycle) untuk mengurangi sampah plastik. Gambar 3.3b menunjukkan hasil kegiatan yaitu satu sistem hidro-vertikultur yang dilengkapi pompa telah terpasang dan ditanami sayuran jenis selada dan kangkung, serta 3 sistem statis dengan kotak sterioform dan beberapa sistem statis menggunakan botol bekas air mineral.

a

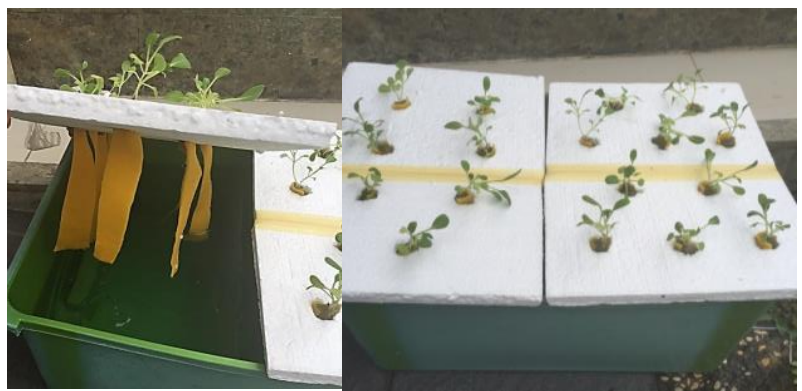

$\mathrm{b}$

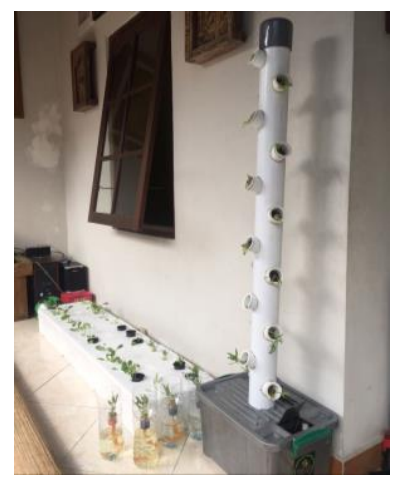

Gambar 3.3. Penggunaan Kotak Bekas Berbahan Plastik sebagai Wadah Nutrisi dalam Bertanam Sayuran secara Hidroponik (a); Hasil Kegiatan Bertanam Sayuran secara Hidroponik (b)

Kegiatan kedua yang dilakukan pada tanggal 30 September 2018 merupakan kegiatan evaluasi terhadap hasil kegiatan pertama. Gambar 3.4 menunjukkan pertumbuhan tanaman kangkung pada sistem verti-hidrokultur. Tanaman kangkung terlihat tumbuh dengan baik, sedangkan pertumbuhan tanaman selada tidak baik, memiliki ukuran yang kecil dengan jumlah daun yang sedikit. Hal ini dapat disebabkan suhu lingkungan yang kurang sesuai untuk pertumbuhan tanaman selada. Tanaman selada memerlukan suhu sekitar $15^{\circ} \mathrm{C}$ sampai $20^{\circ} \mathrm{C}$ untuk pertumbuhan maksimalnya (Hafiz, 2007). 


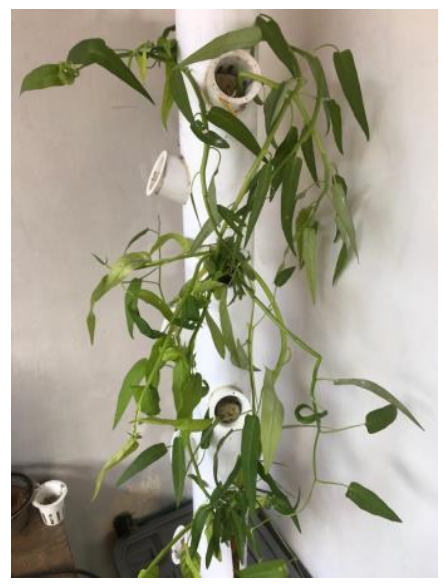

Gambar 3.4. Pertumbuhan Tanaman Kangkung pada Sistem Hidro-vertikultur

\section{KESIMPULAN}

Kegiatan pelatihan budidaya sayuran secara hidro-vertikultur di Desa Datah, Karangasem, Bali, menyediakan alternatif budidaya sayuran tanpa tanah kepada petani, pumuda STT dan masyarakat umum dengan memanfaatkan lahan sempit. Kondisi tanah tandus yang menjadi pembatas dalam bertanam sayuran dapat diatasi dengan sistem hidroponik yang memberikan nutrisi yang tepat sesuai kebutuhan tanaman.

\section{UCAPAN TERIMAKASIH}

Kegiatan ini didanai oleh DIPA PNBP Universitas Udayana Tahun Anggaran 2018 Sesuai dengan Surat Perjanjian Penugasan Pelaksanaan Hibah Pengabdian Kepada Masyarakat Udayana Mengabdi dan Hibah Udayana untuk Masyarakat Dana PNBP pada Lembaga Penelitian dan Pengabdian Kepada Masyarakat Universitas Udayana Tahun 2018 Nomor:384-24/UN14.4.A/PM/2018, tanggal 29 Maret 2018

\section{DAFTAR PUSTAKA}

Echeverria, L.P. 2008. Hidroponics for The Home. IICA, Costa Rica.

Hafiz, A.G., 2007. Selada. Agromedia Pustaka. Jakarta

Mas'ud, H. 2009. Sistem Hidroponik dengan Nutrisi dan Media Tanam Berbeda terhadap Pertumbuhan dan Hasil Selada. Media Litbang Sulteng 2:131-136

Nofrinda, 2017. Rancagan Instalasi Hidroponik Vertikultur Sebagai Alternatif Lahan Sempit di Perkotaan. Skripsi. Fakultas teknologi Pertanian, Universitas Andalas, Padang

Nurlaeny, N. 2014. Teknologi Media Tanam dan Sistem Hidroponik. Unpad Press. Jatinangor, Jawa Barat

Roidah, I.S. 2014. Pemanfaatan Lahan Dengan Menggunakan Sistem Hidroponik. Jurnal Universitas Tulngagung Bonoworo 1(2): 143-149.

Rosliani, R., N. Sumarni. 2005. Budidaya Tanaman Sayuran dengan Teknik Hidroponik. Balai Penelitian Tanaman Sayuran Pusat Penelitian dan Pengembangan Hortikultura Badan Penelitian dan Pengembangan Pertanian

Susila, A.D. 2013. Bahan Ajar Mata Kuliah Dasar-Dasar Hortikultura. Departemen Agronomi dan Hortikultura, Fakultas Pertanian, Institut Pertanian Bogor.

https://news.detik.com/berita/3701394/bnpb-dampak-kerugian-ekonomi-akibat-gunung-agung-capai-rp-2-t

https://www.jawapos.com/baliexpress/read/2017/09/23/15229/meski-di-luar-zona-merah-warga-diminta-tak-tidur-lelap 